\title{
Corruption in Health Sector
}

\begin{abstract} Lahore School of Nursing, The University of Lahore, Lahore, Pakistan

Corruption has profound roots in each field in Pakistan. We are on the whole exceptionally mindful of the corruption that keeps running into billions of rupees; however it is the little scale defilement that we don't pay heed, which is gradually spreading its limbs in the public arena. There is expanding interest in health policymaker, organizer and contributors in how debasement influence human services survey and results and what should be possible to battle defilement in health care division. Attempts to explain the peril of abuse of depended control for private increment have reviewed the associations among debasement and various pieces of the board, financing and organization. Direct analysts and anthropologists moreover pointed the individual and social characteristics which sway the lead of government master and client this article present a comprehensives structure for depicting and assessing how openings, weight and legitimization sway defilement in medicinal services area. It is in like manner discusses execution for mediation.
\end{abstract}

${ }^{(1)}$ Rukhsana Manzoor, ${ }^{(2)}$ Sana Sehar, ${ }^{(3)}$ Muhammad Afzal, ${ }^{(4)}$ Prof. Dr. Syed Amir Gillani

Keywords: corruption, health sector

DOI: $10.7176 / \mathrm{JHMN} / 68-14$

Publication date: November $30^{\text {th }} 2019$

\section{Introduction}

Corruption has profound roots in each field in Pakistan. We are on the whole exceptionally mindful of the corruption that keeps running into billions of rupees; however it is the little scale defilement that we don't pay heed, which is gradually spreading its limbs in the public arena. The wellbeing part's essential reason for existing is to serve mankind. In any case, the saviours of life the medicinal staff and emergency clinics have adjusted their jobs and appear to have moved toward becoming individuals from business associations with the sole motivation behind profiting. The corruption that happens in the health care sector is little; however the harm it causes to a patient's life is inconceivable.

The medicinal staff in government hospital not just difficulties the trustworthiness of a regarded and dependable calling, yet in addition makes it unimaginable for a low-salary individual to look for therapeutic assistance when required. The new deceives that human services experts have embraced to redirect additional cash from patients, incorporates requesting fixes to hop the line, stretching out hospital remains so as to drive up charges that the patient owes, and misinforming patients to counsel authorities who charge high expenses. In Pakistan, we have found out about corruption in pharmaceutical organizations, yet the degenerate practices that happen each day in broad daylight and even private hospital, are disregarded.

The expert unfortunate activities can flourish in framework where there are insufficient control or degenerate observing and assessment instruments which is particularly valid for creating nations where the frameworks need straightforwardness and political or open oversight. Health care sector isn't just widespread in creating nations, USA which is one of the most created nations and having most elevated spending plan for wellbeing is additionally influenced broadly.

Anticipating and decreasing defilement in health care sector is a troublesome undertaking especially improvement of viable inspecting and responsibility framework to screen and uphold suitable laws. So as to check the effects of corruption in hospital, administration should progressed which includes a straightforward arrangement or basic leadership procedures including all the partners and intrigue gatherings, for example, enormous Pharma to impact approach creators with equivalent chances and can be guaranteed by reasonable standards of intrigue bunch competition (Brinkerhoff \& Bossert, 2008).

\section{Scenario}

Corruption happens when open specialists who have been given the situation to finish targets, rather use their position and ability to benefit themselves just as other individuals close to them. Defilement in the medical clinic 
may be seen by reviewing the occupations and associations among the different players to recognize potential abuse that are most likely going to occur. This view is indicated the defilement from little to enormous level, some of them referenced as, High cost, low quality offices and development work, High cost, wrong or duplicative medications, Sub-standard equipment and medications, Patients must make casual installments to get drugs, Subremedial or phony medications permitted in market, Violation of individual rights, Reduced usage of administrations by patients who can't pay, Reduced nature of care from loss of income.

Conceptual framework



(Vian, 2008)

As demonstrated by money related theory, specialists measure the costs and favorable circumstances of acting corruptly against the costs and focal points of acting with decency, and choose to act in the way in which that lifts their own situation (Pelayo, Coutiño, \&'n Pelayo, 2001).

\section{Results}

The ongoing media reports have alarmed general society and the legislature however so as to control the therapeutic corruption, part must be finished. Powerful laws and strategies by government, preceded with job of media and solid activity by the administrative body are required. Most importantly, it would be the individual inspiration of the specialists in recalling the promise after turning into a specialist, regard for morals and religion and picking up understanding that can prompt the purifying of the degenerate framework. Despite the fact that we have gone excessively far in such manner however there is constantly an approach to return. Is it accurate to say that we are prepared to return?

Corruption is an entangled issue which undermines an incentive just as prosperity results. Consistently progressively more wellbeing division pioneers are enduring the hostile effects of debasement and the need to address these issues has expansion grounds in their methodologies. Attempts to disengage express parts of defilement in the medical clinic and to grasp its concealed explanation can help with checking the issue. Applying differing pertinent administration hypothesis to nearby settings can make logically fitting operational ventures to diminish debasement, increase pressure on care providers and pioneers and supporter more straightforwardness to ensure the general destinations of human services sector.

Corruption is a great issue which undermines a motivator similarly as wellbeing results. Reliably dynamically more emergency clinics pioneers are persevering through the antagonistic impacts of debasement and the need to address these issues has development grounds in their arrangements. Endeavors to detach unequivocal pieces of defilement in the therapeutic administrations territory and to comprehend its key clarification can 
help with checking the issue. Applying undeniable relevant hypotheses to human services settings can make ceaselessly proper operational exercises to reduce debasement, increment pressure on care suppliers and pioneers and promoter more straightforwardness to guarantee the general goals of wellbeing.

\section{Discussion}

In $2010,42 \%$ of overviewed people revealed accessing health sector facilities by a technique other than standard confirmation, and 48 percent detailed either paying extra expenses for fundamental administrations or being compelled to use the administrations of an assigned affiliate. Of the respondents who were approached to distinguish which gatherings coordinated the degenerate demonstrations, 61\% announced emergency hospital staff, $25 \%$ revealed specialists, and 13\% nurses (Javaid, 2010).

Corruption is most seasoned and common social shrewdness that has existed since commencement of mankind and will stay a changeless reality. corruption can be extensively characterized as "harsh utilization of intensity to fulfill individual or gathering interests" (Haroon, 2014).

Wellbeing is most fundamental needs of peoples; make it a worthwhile objective for corruption. Wellbeing have interesting measurements are defenseless to financial or political impacts and its defilement includes money related motivating forces as well as includes corruption of learning (Schönhöfer, 2004).

This sort of corruption includes twisted actualities and halfway introduction of assessment or proof of research to deceive and to increase out of line edge or market position. Health care sector is regularly positioned among the most degenerate frameworks in many creating nations. Observation review on debasement directed in 23 nations recognized health care sector to be positioned in the main four of every ten nations (Dabalen \& Wane, 2008).

In the time of 2010, 5.6 billion dollars were recovered in blackmail and the larger part; around 2.9 billion dollars were credited to deception in therapeutic administrations sectoralone.6 Pakistan being a making country is moreover overwhelmed by pollution in its social protection system. An examination drove in ghettos of Karachi demonstrated that $68.1 \%$ of the respondents saw that pollution is higher in the organization medicinal facility as appear differently in relation to the private emergency clinic. About $17.8 \%$ patients who search for care at emergency clinic went up against pollution in order to get admitted to these restorative medical hospital (Javaid, 2010).

Data moreover shows the staffs overseeing affirmation, lab staff dealing with the course of action of blood to the patients and medication store staff is the most ruffians. $70 \%$ respondents ensure that they have paid money as remuneration to them sought after by twenty four percent respondents stating that they have paid money as pay off to the experts. The people who paid prizes to pick up induction to helpful thought, $52 \%$ did thusly by paying direct to the human administrations provider (Ahmed \& Ahmed, 2012).

This level playing field for the intrigue gathering will likewise will in general diminish unreasonable campaigning which thus will diminish open doors for maltreatment and facilitate medicinal services conveyance responsible to the population particularly the defenseless gatherings. It is winding up progressively evident that all partners of wellbeing framework including government official, strategy producers, medicinal services suppliers, non-state entertainers and particularly natives should be locked in. The fantasy of common community is not fit enough to sit on arrangement matters should be exposed and medicinal services suppliers needs to acknowledge their job being developed of straightforward and responsive human services framework. Privately sorted out oversight by the common society has demonstrated a ton of guarantee dependent on encounters in Ceara, Brazil and in Bolivia (Lewis, 2006).

At focal level, Governments must spread straightforward point by point spending plan and monetary data identified with wellbeing promptly accessible to open which would then be able to be effectively followed. Satisfactory compensation and execution based budgetary motivators must be guaranteed by the administration for the human services suppliers to improve their activity fulfillment and consequently will make them less helpless against corruption and remuneration. Casual payment can be constrained through setting up elective wellsprings of financing and better administration (Lewis, 2006).

Individuals who don't mean to make casual money are bound to report that they have associations with medicinal work force, which might be substituting for casual installments. Returning to situation degenerate practices are 
wild and have frequently demonstrated unfavorable for patients' security. The administrative body and the legislature have not gone to this issue suitably up until this point.

\section{References}

Ahmed, R., \& Ahmed, Q. M. (2012). Estimation of petty corruption in the provision of health care services: Evidence from slum areas of Karachi. J Economic Sustain Develop, 3(8), 99-110.

Brinkerhoff, D. W., \& Bossert, T. J. (2008). Health governance: concepts, experience, and programming options. Bethesda: Health Systems, 20, 20.

Dabalen, A., \& Wane, W. (2008). Informal payments and moonlighting in Tajikistan's health sector: The World Bank.

Haroon, M. Z. (2014). Corruption in healthcare system: an obstacle in achieving optimal outcome. Journal of Ayub Medical College Abbottabad, 26(2), 109-110.

Javaid, U. (2010). Corruption and its deep impact on good governance in Pakistan. Pakistan Economic and Social Review, 123-134.

Lewis, M. A. (2006). Tackling healthcare corruption and governance woes in developing countries: Center for Global Development Washington DC.

Pelayo, R., Coutiño, R. P., \&'n Pelayo, R. (2001). Gabriel García Márquez: a critical companion: Greenwood Publishing Group.

Schönhöfer, P. S. (2004). Controlling corruption in order to improve global health. International Journal of Risk \& Safety in Medicine, 16(3), 195-205.

Vian, T. (2008). Review of corruption in the health sector: theory, methods and interventions. Health policy and planning, 23(2), 83-94. 